\title{
Changes in Blood Elements Determined by Use of Articaine as a Local Anesthetic in Dental Medicine
}

\author{
MAGDALENA RUSU-NEGRAIA ${ }^{1}$, RUXANDRA SFEATCU ${ }^{2 *}$, DAN NEGRAIA ${ }^{1}$, ANGELICA BENCZE ${ }^{2}$, \\ IOANA STANCIU ${ }^{2}$, MALINA POPA ${ }^{3}$, DAN SERBANOIU ${ }^{4}$, CARMEN LILIANA DEFTA ${ }^{2}$, \\ MARIANA PACURAR ${ }^{4}$ \\ ${ }^{1}$ Dunărea de Jos University, Faculty of Medicine and Pharmacy, Galati, 35 Al. I. Cuza Str., 800010 Galati, Romania \\ ${ }^{2}$ Carol Davila University of Medicine and Pharmacy Bucharest, Faculty of Dental Medicine, 37 Dionisie Lupu Str., \\ 020021 Bucharest, Romania \\ ${ }^{3}$ Victor Babeș University of Medicine and Pharmacy, Timișoara, 2 Eftimie Murgu Sq., 300041 Timisoara, Romania \\ ${ }^{4}$ University of Medicine and Pharmacy Târgu Mureș, 38 Gheorghe Marinescu Str., 540142, Targu Mures, Romania \\ ${ }^{5}$ Titu Maiorescu University of Bucharest, Faculty of Dental Medicine, 67A Gheorghe Petrascu Str., 031593, Bucharest, \\ Romania
}

\begin{abstract}
Local anesthetics are the most efficient substances used to manage pain in dental medicine. Articaine is the only amide-type local anesthetic that contains also an ester group (thiophene group), thus its metabolism occurs both in plasma and in liver. This study aims to determine the haematological changes induced by local and also loco-regional anesthesia with articaine among a group of dental pacients. The values obtained at baseline were compared with those evaluated after 30 and 60 minutes, respectively. Results showed that haematological modifications are minimal and not significant from statistical point of view. Further analysis are recommended for all parameters with continuous modifications during the studied period of time, especially for patients with associated general diseases.
\end{abstract}

Keywords: articaine, haematology, dental anesthesia

The potential of the locoregional anesthesia represents the most physiological anesthesia method and has the widest indications in stomatology [1]. Among the requirements for acceptable dental material are included their quality and performances, their proper composition [2,3]. It is unanimously known that local anesthetics are the most frequently used substances in the dental office. Due to their property to block nervous impulse transmision, local anesthetics are the most effective substances used in pain management in dentistry. Therefore, injecting a certain amount of local anesthetic near the nervous fibers will result in a local anesthesia adequate enough for most of the therapeutical manoevers commonly performed in a dental office. However, similar to any medical substance, local anesthetics too can induce adverse reactions (nervousness, agitation, dizziness, tachypnea) and/or complications (hypertensive crisis, postural hypotension, seizures) [4]. These reactions/complications can be minor due to the local absorbtion of the local anesthetic from the injection site or can be major - signs of cardiac or central nervous system toxicity (generically called Local Anesthetic Systemic Toxicity - LAST) [5,6], The gravity of these reactions/complications depends upon the technique used for the anesthesia, the type of local anesthetic used, the total amount of substance used in one session and upon the associated systemic diseases that the patients have and their medication $[7,8]$.

One of the most frequently used anesthetics in dentistry is articaine, recommended especially for dental procedures that require lenghthy and/or profound pulpal anesthesia [6]. Articaine was first synthetised in 1969 by H. Rusching et. colab. and was introduced in dental practice in 1976 in Germany, in 1983 Canada, and in 2000 in USA. It was approved by FDA (Food and Drug Administration) in 2000 [6]. Articaine is an amide-type local anesthetic chemically and pharmacologically related with both amide type local anesthetics and ester type local anesthetics [8]. Articaine is the only amide-type local anesthetic that also has an ester group (thiophene group) (fig. 1) which makes the biotransformation of articaine to take place both in plasma (hydrolysis by plasma esterase) and in liver (hepatic microsomal enzymes).

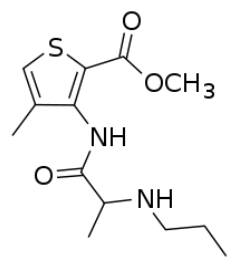

Fig. 1. Chemical formula of articaine [6] 
It's potency is double than that of lidocaine [9] and a toxicity of 1 to 1.5 [6,10]. Articaine's degradation is initiated by hydrolysis of the carboxylic acid ester groups to free carboxylic acid. From that point, the reaction can follow several pathways: cleavage of the carboxylic acid, formation of an acid amino group by internal cyclazation, and oxydation.

Articaine $4 \%$ has a rapid onset of action ( 1 to 2 minutes for the maxilar block, 2 to 3 minutes for mandibular block), the duration of pulpal anesthesia is of 20-40 minutes and that of soft tissues of 2-3 hours [6,7]. Its use is indicated only for local or loco-regional anesthesia in dentistry and maxilo-facial surgery and can be found as a $4 \%$ solution only in combination with epinephrine 1:200.000 or 1:100.000 [11].

\section{Experimental part}

Matherials and method

The present study included 37 clinically healthy pacients. For all these patients both local and loco-regional anesthesia was performed (at different times) using articacaine 4\% with adrenalin 1:200.000. The study is about determining the haematological modifications induced by articaine in clinically healthy pacients. In order to asses these modifications, we collected blood samples before the anesthesia, at 30 minutes and then at 60 minutes after the anesthesia. For each patient we did middle superior alveolar nerve block for the upper first premolar (which we considered to be the standard) and in a different session posterior superior alveolar nerve block (for the upper first molar) because this type of anesthesia is more likely to generate accidents and/or complications [6,7]. The anesthesia was performed by the same person each time, and with the same amount of anesthetic $(1.7 \mathrm{ml})$, for different dental treatments. The blood samples were collected by the same person in tubes specifically designed for the purpose, containing an anticoagulant (EDTA tripotassium/dipotassium/disodium). Complete blood counts (haemogram) was worked using the automatic analyser Sysmex KX21N (BioSystems SA, Spain). A database was set and afterwards was statistically analized using Statistical Package for the Social Sciences (SPSS), version 17.0. We used this software to test statistical hypothesis which is a presumption about a certain parameter of a given distribution or about the law of probability of a studied population [12-15]. For each parameter the values from initial baseline, after 30 minutes and 60 minutes from the anesthesia were compared.

The authors obtained the written informed consent of all pacients included in the study, according to the legislation regarding research involving human subjects. Also, the approval of the Ethical Comitee of "Dunărea de Jos" University was obtained.

\section{Results and discussions}

Modifications in red blood cells number following anesthesia with articaine 4\% and 1:200.000 adrenalin

For the local anesthesia, results show a slight decrease in the number of red blood cells from $5.01( \pm 0.50)$ to $5.00( \pm$ $0.45)$ after 30 minutes from the injection, whereas after 60 the value increases over the baseline, at $5.03( \pm 0.45)$. Results showed that the change in the number of red blood cells is steadily decreasing over the time, but the values don't exceed the reference interval for the clinically healthy pacient (Table 1).

Table 1

HAEMOLEUCOGRAM VALUES FOR CLINICALLY HEALTHY PATIENT [9, 14, 15]

\begin{tabular}{||l||l|l||}
\hline \hline Parameter & Female & Male \\
\hline \hline$W B C \times 10^{3} / \mu L$ & $4.0-10.5$ & $4.0-10.5$ \\
\hline$R B C \times 10^{6} / \mu L$ & $4.2-5.4$ & $4.7-6.0$ \\
\hline$H G B g / d L$ & $11.0-16.0$ & $12.0-18.0$ \\
\hline$P L T \times 10^{3} / \mu L$ & $150-450$ & $150-450$ \\
\hline
\end{tabular}

Results presented in Table 2 show no significant differences between the values at baseline, after 30 minutes and after 60 minutes from the local anesthesia (the degree of confidence of accepting the null hypothesis > 0.05). Even if there are important changes after local anesthesia with articaine 4\% and 1:200.000 adrenalin, the values don't exceed the reference interval for the clinically healthy pacient. After the loco-regional anesthesia, the dynamics of the number of red blood cells shows a slight decrease from $5.01( \pm 0.50)$ to $4.87( \pm 0.38)$ after 30 minutes, and then decreases further to a mean of $4.84( \pm 0.56)$ after 60 minutes. It was found that statistically significant changes occurred between baseline and 60 minutes from anesthesia (the degree of confidence of accepting the null hypothesis $=0.000<0.05$ ) (Table 2 ). 
Table 2

COMPARED ANALYSIS OFTHENUMBER OF RED BLOODCELLS BEFORE THE ANESTHESIA, AFTER 30 MINUTES AND AFTER 60 MINUTES USING4\% ARTICAINE WITH 1:200.000 ADRENALIN

\begin{tabular}{|c|c|c|c|c|c|}
\hline \multicolumn{6}{|c|}{ Paired Differences } \\
\hline \multirow[t]{2}{*}{ Red blood cells count } & \multicolumn{2}{|c|}{$\begin{array}{c}95 \% \text { Confidence } \\
\text { Interval of Difference }\end{array}$} & \multirow[b]{2}{*}{$\mathrm{t}$} & \multirow[b]{2}{*}{$\mathrm{df}$} & \multirow[b]{2}{*}{$\begin{array}{l}\text { Sig.(2- } \\
\text { tailed) }\end{array}$} \\
\hline & Lower & Upper & & & \\
\hline \multicolumn{6}{|l|}{ Local anesthesia } \\
\hline Baseline - 30 minutes & -.02747 & .04801 & .552 & 36 & .584 \\
\hline Baseline -60 minutes & -.05816 & .02897 & -.679 & 36 & .501 \\
\hline $30-60$ minutes & -.06767 & .01794 & -1.178 & 36 & .246 \\
\hline \multicolumn{6}{|l|}{ Loco-regional anesthesia } \\
\hline Baseline - 30 minutes & -.03797 & .32662 & 1.606 & 36 & .117 \\
\hline Baseline - 60 minutes & .09943 & .25787 & 4.573 & 36 & $.000 *$ \\
\hline $30-60$ minutes & -.17611 & .24476 & .331 & 36 & .743 \\
\hline
\end{tabular}

Modifications in haemoglobinemia following anesthesia using articaine 4\% with $n$ 1:200.000 adrenalin

For local anesthesia, was observed a slight increase of the haemoglobinemia values from $14.52( \pm 2.22)$ to $14.59( \pm$ $1.98)$ in the first 30 minutes, and after another 30 minutes, the values increase to $14.61( \pm 2.00)$ over the baseline values. After the stastistical analysis, we observed no significant differences between the initial value, the 30 minutes value and the 60 minutes value (the safety degree of accepting the null hypothesis > 0.05) (Table 3).

Table 3

COMPARED ANALYSIS OF HAEMOGLOBINEMIA BEFORE, AFTER 30 MINUTES AND AFTER 60 MINUTES FROM ANESTHESIA USING 4\% ARTICAINE WITH 1:200.000 ADRENALIN

\begin{tabular}{|c|c|c|c|c|c|}
\hline \multirow{3}{*}{ Haemoglobinemia } & \multicolumn{5}{|c|}{ Paired Differences } \\
\hline & \multicolumn{2}{|c|}{$\begin{array}{l}95 \% \\
\text { Interval of Difference }\end{array}$} & \multirow[b]{2}{*}{$\mathrm{t}$} & \multirow[b]{2}{*}{$\mathrm{df}$} & \multirow[b]{2}{*}{$\begin{array}{ll}\text { Sig. } & (2- \\
\text { tailed })\end{array}$} \\
\hline & Lower & Upper & & & \\
\hline \multicolumn{6}{|l|}{ Local anesthesia } \\
\hline Baseline - 30 minutes & -.31743 & .17149 & -.605 & 36 & .549 \\
\hline Baseline - 60 minutes & -.33792 & .15955 & -.727 & 36 & .472 \\
\hline $30-60$ minutes & -.13475 & .10232 & -.277 & 36 & .783 \\
\hline \multicolumn{6}{|c|}{ Loco-regional anesthesia } \\
\hline Baseline - 30 minutes & .07911 & 1.51008 & 2.252 & 36 & $.030 *$ \\
\hline Baseline - 60 minutes & -.85471 & .26552 & -1.067 & 36 & .293 \\
\hline $30-60$ minutes & -1.86249 & -.31588 & -2.857 & 36 & $.007 *$ \\
\hline
\end{tabular}

It should be noted that although hemoglobinemia undergoes large changes, in the time interval under study, these modifications do not exceed the reference values for the clinically healthy patient (Table 1). After the loco-regional anesthesia we noticed a decrease of haemoglobinemia values from $14.52( \pm 2.22)$ to $13.72( \pm 1.71)$, and after another 30 minutes, an increase over the baseline, up to 14.81 ( \pm 1.47$)$. Based on the statistical analysis, we found that there were significant differences between baseline and 30 minutes, respectively between 30 and 60 minutes from anesthesia (the degree of confidence of accepting the null hypothesis $=0.030<0.05$ and $0.007<0.05$, respectively) (Table 3). Although haemoglobinemia values have an important fluctuant evolution, these changes don't exceed the normal values for the clinically healthy patient (Table 1).

Modifications in the number of platelets count after anesthesia using articaine 4\% with 1:200.000 adrenalin

It was noticed a rapid increase in the number of platelets after 30 minutes after the local anesthesia from $263.70( \pm$ $58.20)$ to 267.18 ( \pm 66.25$)$, and also increase after another 30 minutes to $269.83( \pm 63.11)$. Statistic analysis revealed no significant differences between the baseline and the values after 30 minutes and after 60 minutes (the safety degree of accepting the null hypothesis $>0.05$ for all three paires compared) (Table 4). 
Table 4

COMPARED ANALYSIS OF PLATELETS NUMBER BEFORE, AFTER 30 MINUTES AND AFTER 60 MINUTES FROM ANESTHESIA USING 4\% ARTICAINE WITH 1:200.000 ADRENALIN

\begin{tabular}{|c|c|c|c|c|c|}
\hline \multirow{3}{*}{ Platelet counts } & \multicolumn{5}{|c|}{ Paired Differences } \\
\hline & \multicolumn{2}{|c|}{$\begin{array}{l}95 \% \text { Confidence } \\
\text { Interval of Difference }\end{array}$} & \multirow[b]{2}{*}{$\mathrm{t}$} & \multirow[b]{2}{*}{$\mathrm{df}$} & \multirow[b]{2}{*}{ Lower } \\
\hline & Lower & Upper & & & \\
\hline \multicolumn{6}{|l|}{ Local anesthesia } \\
\hline Baseline - 30 minutes & -14.12266 & 7.14969 & -.665 & 36 & .510 \\
\hline Baseline - 60 minutes & -16.34092 & 4.07065 & -1.219 & 36 & .231 \\
\hline $30-60$ minutes & -5.80411 & .50681 & -1.702 & 36 & .097 \\
\hline \multicolumn{6}{|c|}{ Loco-regional anesthesia } \\
\hline Baseline - 30 minutes & -27.91508 & 27.86102 & -.002 & 36 & .998 \\
\hline Baseline - 60 minutes & 8.76785 & 86.85377 & 2.484 & 36 & $.018 *$ \\
\hline $30-60$ minutes & 5.10335 & 90.57232 & 2.270 & 36 & $.029 *$ \\
\hline
\end{tabular}

The values increase continuously, but do not exceed the reference interval for clinically healthy patient (Table 1).

With regard to the loco-regional anesthesia with articaine 4\% and 1:200.000 adrenalin, we observed that the number of platelets are almost unchanged in the first 30 minutes of anesthesia, increase from $263.70( \pm 58.20)$ to $263.72( \pm$ $79.43)$, then suddenly decrease in the next 30 minutes to the mean of $215.89( \pm 88.80)$. Based on the statistical analysis, there were significant differences between baseline and 60 minutes, respectively between 30 minutes and 60 minutes (the safety degree of accepting the null hypothesis $=0.018<0.05$ and $0.029<0.05$, respectively) (Table 4). The platelet count is almost unchanged in the first 30 minutes, then in an important decrease in the next 30 minutes, but still the values do not exceed the baseline for the clinically healthy patient (Table 1).

\section{Modifications in white blood cell count after anesthesia using articaine 4\% with 1:200.000 adrenalin}

After the local anesthesia, it was noticed an increase in white blood cell count from 7478,37 ( \pm 1893.57$)$ to 7591.89 ( \pm 1666.56) during the first 30 minutes after the anesthesia, values which continue to increase up to $7597.30( \pm 1700.24)$ after another 30 minutes from the injection. Even if there is a continuous increase in the number of white blood cells following local anesthesia with articaine $4 \%$ and adrenaline 1:200.000, the statistical analysis shows no significant modifications (the safety degree of accepting the null hypothesis > 0.05) (Table 5) and the means don't exceed the normal values for the clinically healthy patient (Table 1).

Table 5

COMPARED ANALYSIS OF THE NUMBER OF WHITE BLOOD CELLS BEFORE, AFTER 30 MINUTES AND AFTER 60 MINUTES FROM ANESTHESIA USING4\% ARTICAINE WITH 1:200.000 ADRENALIN

\begin{tabular}{|l|l|l|l|l|l|}
\hline \multirow{3}{*}{ White blood cells count } & Paired Differences & & \\
\cline { 2 - 6 } & \hline $\begin{array}{l}\text { 95\% Confidence Interval of } \\
\text { Difference }\end{array}$ & & & \\
\cline { 2 - 6 } & Lower & Upper & $\mathrm{t}$ & $\mathrm{df}$ & Lower \\
\hline \hline Local anesthesia & & & & & \\
\hline Baseline - 30 minutes & -343.72959 & 116.70256 & -1.000 & 36 & .324 \\
\hline Baseline -60 minutes & -370.99082 & 133.15298 & -.957 & 36 & .345 \\
\hline 30-60 minutes & -107.55223 & 96.74142 & -.107 & 36 & .915 \\
\hline \hline Loco-regional anesthesia & & & & & \\
\hline Baseline -30 minutes & 23.83196 & 1732.92480 & 2.085 & 36 & $.044^{*}$ \\
\hline Baseline-60 minutes & -206.89236 & 1736.62209 & 1.596 & 36 & .119 \\
\hline 30-60 minutes & -993.02729 & 766.00026 & -.262 & 36 & .795 \\
\hline \hline
\end{tabular}

As for the loco-regional anesthesia, was noticed an important decrease in white blood cells count after 30 minutes after the anesthesia, from a baseline of $7478.37( \pm 1893.57)$ to $6600.00( \pm 1319.72)$ in the first 30 minutes, then the values begin to increase up to $6713.51( \pm 1879.88)$, with the tendency to return to the initial values. The statistical analysis shows significant modifications only between baseline and the values after 30 minutes (the safety degree of accepting the null hypothesis $=0.044<0.05)($ Table 5). The number of white blood cells is fluctuent in the interval of time studied, but also without exceeding the reference values for the clinically healthy patient (Table 1).

The results of the present study showed that the haematological changes for a period of 60 minutes following local or loco-regional anesthesia with 4\% articaine with 1:200.000 adrenalin are minimal and not statistically significant. There are certain parameters, which taken separately have small diagnostical value, that increase or decrease continuouslly during the time interval studied and don't show signs of compensating after 60 minutes from the anesthesia.

Red blood cells number are in a slight increase compared with the initial values after 60 minutes from the anesthesia, for both techniques. Haemoglobinemia's dynamics is different for the two techiques used: when local anesthesia is used, REV.CHIM.(Bucharest) $\$ 70$ no. $12 \downarrow 2019$ 
we noticed a significant increase in the first 30 minutes and the values continued to increase surpassing the initial value, but not surpassing the baseline values. When loco-regional anesthesia is performed, haemoglobinemia's values decrease significantly in the first 30 minutes, then, after another 30 minutes values increase, surpassing the initial values but not surpassing the baseline values. The number of platelets increases continuously during the 60 minutes after the injection when middle alveolar nerve block is obtained, without without exceeding the baseline values. For the posterior superior alveolar block, the number of platelets doesn't change, then, after another 30 minutes, it suddenly decreases without exceeding the baseline values. White blood cells number increases continuously after the local anesthesia, but decreases rapidly in the first 30 minutes after loco-regional anesthesia, then increases slowly without reaching the initial values. Neither for the local anesthesia, nor for the loco-regional anesthesia white blood cells count doesn't exceed the baseline values. The number of red blood cells has little diagnostical value, it is associated with haemoglobinemia and/or haematocrit values.

\section{Conclusions}

The results revealed that parameters (haemoglobinemia, number of platelets, and number of white blood cells) that have continuous modifications during the time interval studied are related with the loco-regional anesthesia.

The decrease of these three parameters is met in anemias and because our study showed a continuous decrease in haemoglobinemia 60 minutes after loco-regional anesthesia, 4\% articaine with 1:200.000 adrenalin should be administered with caution to anemic dental patients. Further analysis are recommended for parameters which showed continuous modifications during the time interval studied, especially among subjects with associated general diseases.

The dentists should improve knowledge about the clinical guides of surgery and dental practices and also about the newest commercial anesthetic products available for dentistry.

\section{References}

1.SCUTARIU, M.M., DANILA, V., CIUPILAN, C., CIURCANU, O.E., Rev. Chim. (Bucharest), 68, no. 10, 2017, p. 2373- 2377

2.BECHIR, E.S., BECHIR, A., GIOGA, C., MANU, R., BURCEA, A., DASCALU, I.T., Mat. Plast., 53, no. 3, 2016, p. 394-398

3.GIOGA, C., BECHIR, E.S., CURT MOLA, F., DEFTA, C.L., BECHIR, A., et al, Rev. Chim. (Bucharest), 68, no. 12, 2017, p. 2974- 2977

4.MALAMED, S.F., Medical emergencies in the dental office, $7^{\text {th }}$ Edition, Elsevier Mosby, 2015 , p. $60-105,360-393$

5.***ASRA, Practice Advisory on Local Anesthetic Systemic Toxicity: www.asra.com

6.MALAMED, S.F., Handbook of Local Anesthesia, 6 ${ }^{\text {th }}$ Edition, Elsevier Mosby, 2012, p. 3 - 82

7.BUCUR, Al., VILA, C.N., LOWRY J., ACERO J., Compendiu de chirurgie oro-maxilo-facială, vol. 1, Q Med Publishing, București, 2009, p. $3-17$

8.CIURCANU, O.A., STEFANESCU, O., SCUTARIU M.M., STELEA C.G., Rev. Chim. (Bucharest), 67, no. 3, 2016, p. 566

9.BARTL, R., THOMAS, L., Clinical Laboratory Diagnostics: Use and Assessment of Clinical Laboratory Results, $1^{\text {st }}$ Edition, TH-Books, 1998, p. $509-517$

10.LEE, J., LEE, JY, HYUN JEONG KIM, H.J., SEO, K.S., Dental anesthesia for patients with allergic reactions to lidocaine: two case reports, Journ. Dent. Anesth. Pain Med., 16, no. 3, 2016, p. 209

11.PERTEA, M., POROCH, V., GROSU, O.M., LUNCA, S., Rev. Chim. (Bucharest), 69, no. 1, 2018, p. 169

12.MOORE, D.S., MCCABE, G.P., CRAIG, B.A., Introduction to the Practice of Statistics, $6^{\text {th }}$ edition, W.H. Freeman and Company, 2007, p. 171, 311-343, 356-368

13.WACKERLY, D.D., MENDENHALL, W., SCHEAFFER, R.L., Mathematical Statistics with Applications, $7^{\text {th }}$ edition, Thomson Brooks/Cole, 2007, p. 3-8, 661-667, 741-755.

14.FISCHBACH, F., DUNNING, M., A Manual of Laboratory and Diagnostic Tests, $9^{\text {th }}$ Edition, Wolters Kluwer Health / Lippincott Williams \& Wilkins, 2014, p. 38-161

15.GREER, J.P., ARBER, D., GLADER, B., LIST A., MEANS, R.T. Jr, PARASKEVAS, F., RODGERS, G.M., Wintrobe's Clinical Hematology, $13^{\text {th }}$ Edition, Wolters Kluwer Health/Lippincott Williams \& Wilkins, 2013: p. 3-21, 268-303, 311-329, 409-433, 948-975, 1495-1505, 15291531, 1565-1570, 1591-1597, 1777-1795.

Manuscript received: 12.12 .2018 